\title{
Special economic zones in Poland - the assumptions and effects
}

\author{
Katarzyna Przybyla* and Alina Kulczyk-Dynowska
} Department of Spatial Development, Wroclaw University of Environmental and Life Sciences, Grunwaldzka Street 53,
50-357 Wroclaw, Poland.

Accepted 5 October, 2012

\begin{abstract}
The aim of this study is to explain the principles of the creation, operation and analysis of the effects of special economic zones. Zones are a tool of regional policy, aiming at accelerating the economic development of disadvantaged areas. Attracting capital activates specific areas of the economy, allows beneficial transformations into its structure and allows for the creation of new jobs. One factor that influenced the development of special economic zones in Poland was country's accession to the European Union. Access to the common market, tax benefits and relatively low labor costs have led investors to undertake activities in the zones. Research which help to understand the impact of special economic zones on socio-economic development is important, useful in deciding whether to continue their functioning or not. Results can also be useful for practitioners of economic when it comes to making a decision about starting new business in the sphere.
\end{abstract}

Key words: Special economic zone, regional policy.

\section{INTRODUCTION}

Special Economic Zones (SEZ) in Poland operate under the Act on Special Economic Zones of 20 October 1994, as amended (Journal of Laws (J.L.) 2007.42.274, changes: J.L.2008.118.746 - Article (Art.) 1, J.L.2009.18.97- Art.12). SEZ - in Mielec - was founded in 1995, the youngest is the Krakowska zone, which began operations in the year 1998. Currently there are fourteen special economic zones present in all Polish provinces. These are: Kamiennogorska SEZ Small Businesses, Katowicka SEZ, Kostrzynsko-Slubicka SEZ, Krakowska SEZ, Cracow Technology Park, Legnica SEZ, Lodzka SEZ, Mielecka SEZ Euro-Park Mielec, Pomorska SEZ, Slupska SEZ, Starachowicka SEZ, Suwalska SEZ, Tarnobrzeska SEZ Euro-Park Wislosan, Walbrzyska SEZ Invest-Park and Warminsko-Mazurska SEZ. The total area of the zones in 2010 was 14,107 ha, located in 135 cities and 192 communities. In accordance with the

*Corresponding author. E-mail: katarzyna.przybyla@up.wroc.pl. Tel: +48713205409. Fax: +48713205607.

Abbreviations: SEZ, special economic zone; J.L., Journal of Laws; EU, European Union; PLN, Polish zloty, currency valid in Poland; Art., article. provisions currently in force, SEZ will be in full operation in 2020.

The factor that influenced the development of SEZs in Poland, was long planned and implemented in 2004 during the country's accession to the European Union (EU). Access to the common market, tax benefits and relatively low labor costs have prompted numerous investors to take up activities in the zones.

The aim of this study is to explain the principles of the creation, operation and analysis of the effects of the SEZ in Poland. Zones are macroeconomic tool of regional policy, aimed at the harmonious development of the specific areas. By creating favourable conditions for investors, they contribute to increasing competitiveness of economy. Studies, which help to understand the impact of the special economic zones on the socioeconomic development -can be useful. The result may be useful also for practitioners of economic life when deciding about starting the activities in the zone.

\section{SPECIAL ECONOMIC ZONES IN POLAND AND THE EU REGIONAL POLICY}

Important role in the establishment and functioning of 
SEZs in Europe plays EU regional policy whose primary goal is to reduce and equalize disparities and thus the rising of the backwardness of the less-developed countries (Filipiak et al., 2005). Activity in the SEZ is subjected, in the light of EU regulations, to the regional state aid. It applies to those areas where per capita GDP is less than $75 \%$ of EU average. It is worthy to mention that, by 2010 , only one of the sixteen Polish provinces Masovian one- exceeded this value.

Planned Polish EU membership has led to the need to adjust the law in force in Poland, also of the functioning of SEZs to the solutions adopted in the Union. Also, the Act on SEZ passed in 1994 was incompatible with, signed by Poland in 1991, Europe Agreement establishing an association between RP and the European Communities (J.L.1994.11.38). According to it, any public aid which distorts or threatens to distort competition is not allowed; the EU adopted the position that public aid for companies operating in the zone, granted in accordance with the original version of the Act on SEZ violates the principle of fair competition (Przybyla, 2010). Subsequent amendments to the Act on special economic zones have adapted it to the EU law, and also due to changes in Community legislation at the beginning of each budget period in the EU, SEZ adaptation to EU rules on regional aid is a cyclical process (Report ..., 2011).

While the European Union allows for public assistance it provides it with clauses. The aid must be limited in time, premises supported by socio - economic reasons, and it must not exceed the limit. SEZs in Poland will be in operation by 2020 , although it should be noted that the date of liquidation has already been postponed.

\section{THE ESSENCE OF SPECIAL ECONOMIC ZONES}

A special economic zone is isolated, in accordance with the provisions of the Act, uninhabited part of Polish territory, where the economic activity may be conducted under the terms of paragraph J.L.2007.42.274, Art. 2. In accordance with the basic premises, zones are intended to serve raising capital in order to activate the economy of the region (Broszkiewicz, 2011). Fiedor (2007) referring to the classical model of business location of Smith (1966) notes that the area is a form of subsidization of investors, with the aim of directing them to places that otherwise would not be of interest to them. These areas are located either outside the spatial limits of profitability or are perceived by investors as less attractive in comparison with the competitive locations.

It can therefore be assumed that the SEZ is one of the instruments of regional policy aimed at attracting capital for selected areas of economic revival and accelerating in this way their economic development (Kirylo, 2000; Mikolajewicz 2000). Entrepreneurs exercising their investment projects in a SEZ are offered subsidize package of services in the form of state aid (Sadowski et al., 1999).

The zone is created by the Council of Ministers, at the request of the minister responsible for the economy (Jaslan, 2009). It is worth noting that he or she is required to obtain the consent of the municipal council which is the host of this site plus also seek the opinion of the voivodeship board (J.L.2007.42.274, Art. 4). Under the law each of the SEZ could only be managed by a limited company, or limited liability company in which the State or local government holds a majority of votes. The company's supervisory board members include representatives of local government units, so we can talk about an important impact on the functioning of these characterized entities.

Permit for conducting business activity within the zone is the basis for the use of public assistance. It sets out, among others, object of the entrepreneur's activity, specify the conditions for employment of a certain number of employees and investment value. Permits is granted by the minister competent for economic affairs, after consultation with manager. Another condition is that taking up the business will contribute to achieving the objectives, as defined in its development plan. Determining who obtains a permit, is done by tender or prognosis taken on the basis of public invitation (J.L.2007.42.274, Art. 16 and 17). Relatively high lower limit of the value of the investment (100 thousand euro) that makes micro companies may not lead preferentially taxable activities in these areas (Bartosiewicz and Marszal, 2011).

The entrepreneur who decided to start operations in the SEZ can count on certain privileges. They rely primarily on the exemption of the income tax. Admissible amount of aid the entrepreneur can get depends on; investment location, investment amount, the employment of new employees, as well as the size of the company applying for tax exemption.

Company operating under the authorization granted in the SEZ can benefit from assistance from the region from two titles: capital expenditure or the creation and maintenance of new urban conservation. It is also possible to use both of these forms at the same time, provided that the total aid does not exceed maximum permissible aid volume for given investment.

1. Aid for new investment - is exempt from income tax payable because of the income derived from business done in the SEZ area which is max $50 \%$ of capital expenditure (or max respectively 70 and $60 \%$ in the case of small and medium enterprises.)

In the case of an investor taking advantage of public assistance due to the costs of new investment, the expenses that are included in the costs are as follow:

(i) the cost of acquisition of land or the right of perpetual usufruct,

(ii) the purchase price or the cost of manufacturing in- 
house assets, provided they pass to the taxpayer's assets,

(iii) cost of expansion or modernization of existing fixed assets,

(iv) the cost of intangible and legal assets related to technology transfer through the acquisition of patent rights, licenses, know - how or not patented technical knowledge,

(v) cost associated with renting or leasing land, buildings and structures- provided that the lease period lasts long enough,

(vi) the purchase price of assets other than land and buildings will be covered by the rent or lease where the rent or lease has the form of financial leasing and includes a commitment to purchase the asset after a specified period of time.

2. Aid for employment (job creation) - exemption from income tax payable due to the revenues generated from economic activity conducted in the SEZ in the amount of up to $50 \%$ (or up to $70 \%$ and $60 \%$ for small and medium companies)- conducted on the two-year labor costs of newly employed workers. The size of regional aid for job creation is calculated with regard to the value incurred by the entrepreneur- 2-year labor costs of newly recruit employees which consists of gross wage costs of employees increased by all obligatory premiums associated with their employment (J.L.2008.232.1548, § 3 and 6).

Company operating in the zone is required to ensure the sustainability of investments or employment for a period of at least 5 years, and in the case of small and medium-sized enterprises at least by 3 years.

The allowable amount of assistance for each region Polish, and hence for each zone, defines the regional aid map. From 1 January 2007, on the basis of the Council of Ministers of 13 October 2006, in Poland the Map of regional aid is obligatory for the period of years 2007 to 2013 (J.L.2006.190.1402). Additionally, the document lists the types of economic activities for which grant support is not allowed and the types of economic activity for which the maximum amount of aid is different than the standard. For example, there are different rules for granting aid for large investment project-its size is limited.

In the literature by Czerwinska (2000), Krynska (2000; 2000a) and Trojak et al. (2009) certain allegations against Polish SEZ are formulated. They concern most often:

(i) The effect of idle run that is investments in the zones would take place regardless of the fact of their existence, and thus the establishment of SEZs was unnecessary;

(ii) Substitution effect: This is as a result of action by a business entity in the zone, followed by elimination or significant reduction of its activity in another area;

(iii) Crowding-out effect: where assistance to entrepreneurs in the areas gives them a competitive advantage, allowing for expulsion from the market companies in the business of a similar nature;

(iv) Enclave effect: When a company located in the zone are not affiliated with the regional environment, the benefits they use materials supplied from outside the region and parts production, who then sell outside the region (Gwosdz and Domanski, 2005).

There is some risk associated with the fact that after the liquidation of SEZ, and thus the loss of privilege some operators choose not to pursue activities in the current location. Flow of the capital to more competitive regions will create the risk for the whole Polish economy (Broszkiewicz, 2011). This situation may also occur in the case when the company gets better conditions earlier (before the year 2020) for investing outside the zone boundary in Poland. It seems very probable as you can move relatively easy modern technological lines. It is therefore necessary to take action to protect the local economy against the negative effects of described situations (Przybyla, 2010).

\section{EFFECTS OF THE FUNCTIONING OF SPECIAL ECONOMIC ZONES}

Effectiveness of the SEZ is usually assessed through the prism incurred by the business zone and the emerging investment locations. Additional criteria are: the degree of development of the zones and the number of permits for business activity in the SEZ.

Table 1 contains basic information about the state of Polish SEZ in 2010. Investments with the highest value per 1 ha area were collected in Katowicka SEZ (1.98 mln EUR / 1 ha), Walbrzyska SEZ (1.62 mln EUR / 1 ha) and Lodzka SEZ (1.54 mln EUR / 1 ha). These zones are also characterized by above-average number of valid permits to economic activity. The least invested were: Slupska SEZ (0.54 million / 1 ha) and Starachowicka SEZ (0.58 million EUR/1 ha).

In Katowicka, Lodzka and Walbrzyska SEZ, the most jobs were created and maintained per 1 ha of the zone (consequently 22.7, 17.8, 19.4/ 1 ha). Preferably, in this respect Tarnobrzeska SSE (17.9), Suwalska (17.4) and Krakowska Special Economic Zone (17.1) were estimated. The worst result was in Slupska SEZ (6.7).

In 2004, the total area cultivated in the SEZ was $54.8 \%$, and in 2010,62.3\%. It should be noted that in the meantime, the area of zones increased by more than 7580 ha. This explains the fact that the degree of development of some areas such as the Walbrzyska, or Legnicka Special Economic Zone decreased.

It can be seen that the number of jobs created by zone entrepreneurs since 2000, steadily increased (Figure 1). Employment in 2002 in relation to the initial period was about $60 \%$ higher in 2004 by $53 \%$ higher than two years earlier. In 2006, the rate of growth of the number of jobs 
Table 1. SEZ in Poland - size of investment, jobs, the degree of development, permits. As on December 31, 2010 (1 EUR to 4.44 PLN - rate on 21.12.2011 r.).

\begin{tabular}{|c|c|c|c|c|c|c|c|}
\hline On & The name of the zone & $\begin{array}{c}\text { The volume of investment } \\
\text { (EUR million) }\end{array}$ & Workplaces & $\begin{array}{c}\text { Zone area } \\
\text { (ha) }\end{array}$ & $\begin{array}{c}\text { The degree of land } \\
\text { use (\%) }\end{array}$ & $\begin{array}{c}\text { The degree of } \\
\text { development w } 2004 \text { r. (\%) }\end{array}$ & $\begin{array}{c}\text { No. of valid } \\
\text { permits }\end{array}$ \\
\hline 1 & Kamiennogorska SEZ & 349.16 & 4349 & 367.1 & 49.8 & 42.6 & 46 \\
\hline 2 & Katowicka SEZ & 3797.41 & 43473 & 1917.7 & 53.1 & 57.1 & 201 \\
\hline 3 & Kostrzynsko-Slubicka SEZ & 852.31 & 17252 & 1267.5 & 62.1 & 34.6 & 112 \\
\hline 4 & Krakowska SEZ & 372.70 & 8936 & 523.4 & 61.6 & 33.2 & 58 \\
\hline 5 & Legnicka SEZ & 1028.45 & 8803 & 1041.8 & 27.0 & 56.9 & 53 \\
\hline 6 & Lodzka SEZ & 1842.43 & 23248 & 1198.7 & 67.2 & 60.9 & 142 \\
\hline 7 & Mielecka SEZ & 1055.80 & 16516 & 1135.0 & 70.3 & 79 & 150 \\
\hline 8 & Pomorska SEZ & 1514.36 & 19275 & 1240.0 & 76.7 & 71 & 75 \\
\hline 9 & Slupska SEZ & 216.91 & 2683 & 401.1 & 60.9 & 49.4 & 45 \\
\hline 10 & Starachowicka SEZ & 344.16 & 6349 & 595.8 & 62.2 & 53.2 & 70 \\
\hline 11 & Suwalska SEZ & 332.01 & 5958 & 342.8 & 68.7 & 65.2 & 56 \\
\hline 12 & Tarnobrzeska SEZ & 1368.94 & 27832 & 1551.9 & 67.7 & 42.3 & 121 \\
\hline 13 & Walbrzyska SEZ & 2724.97 & 30057 & 1685.1 & 67.9 & 73.6 & 159 \\
\hline 14 & Warminsko-Mazurska SEZ & 682.83 & 10558 & 838.9 & 71.1 & 17.7 & 66 \\
\hline Total & & 16482.44 & 225289 & 14106.8 & 62.3 & 54.8 & 1354 \\
\hline
\end{tabular}

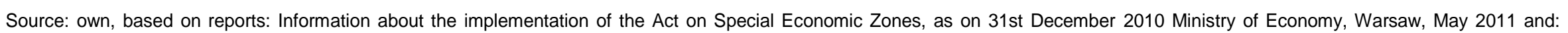
Special economic zones as of 31 December 2004 Ministry of Economy and Labour, Warsaw, March 2005.

reached a record $89 \%$, which is equivalent to the functioning of 68.85 thousand additional jobs. In relation 2008/2006 the increase reached $44 \%$. From 2008 to 2010 it was the lowest and amounted to only $7 \%$. This is because it was in these years that the first wave of economic crisis reached Poland. Therefore, it can be assumed that a significant decrease in growth rate in the number of jobs in the SEZ was its effect. Taking into account the significant share of foreign capital invested in the zones in 2010, the total share of Polish entities in capital expenditures amounted to $17.33 \%$. It also allows the assumption that there is a high dependence of the characterized instrument of regional policy from the business cycle.

Capital expenditure incurred by businesses in the SEZ from year to year were getting higher and higher (Figure 2). Its size was characterized by a significant growth. From 2006 to 2008 , investment grew by a record 4.79 billion euros, which corresponds to growth of about $60 \%$. In another tested 2 year period its value was still increasing, but significantly less - about 3.72 billion euros, that is approximately $29 \%$ compared to 2008 .

It is worth noting that in the sub-zone in which they operate, the level of GDP per capita was higher on average by about 1300 to 2500 PLN (EUR 293 to 563) than in other subregions. At the same time an increase in employment in the zones of a thousand people led to an increase in GDP per capita in the sub-region by about 310 to 460 PLN (EUR 70 to 104) (Report ..., 2011). Favourable conditions of operation of businesses in the zones meant that many foreign and national companies located their premises there. It consequently, brought about the favourable transformations in the subregion's economy structures (Przybyla, 2010a).

\section{Conclusion}

In 1989, a multi-annual process of transformation of both the system and the system of the state began in Poland. Ongoing transformation of the socio-economic - economic development have resulted in growing intensity of developmental processes occurring in the country. Unfortunately, they focused mainly in the larger cities and in the developed industrial centres. Many areas with lower levels of infrastructure management or 


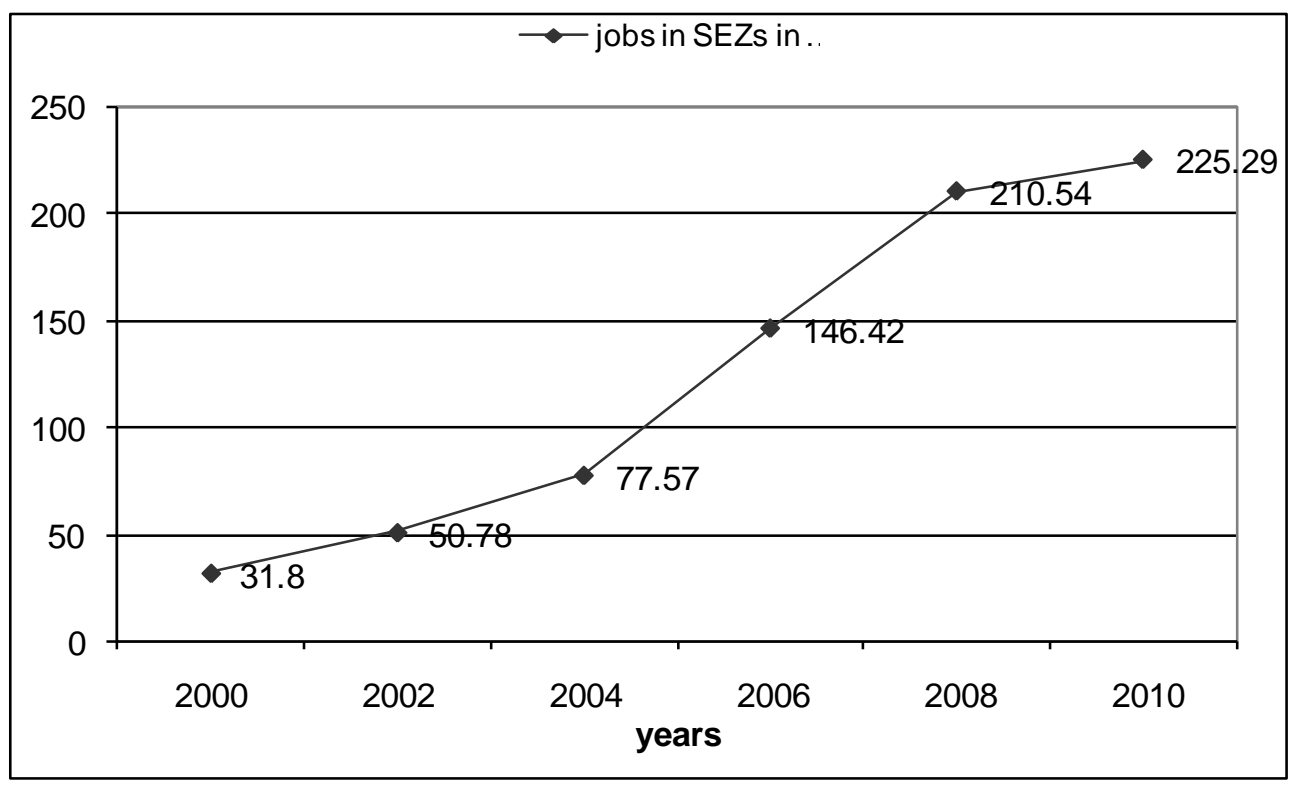

Figure 1. Jobs in the SEZs in the years 2000 to 2010.

Source: own, based on reports: Special economic zones, as of December 31, 2004, Ministry of Economy and Labour, Warsaw, March 2005, Information on the implementation of the Act on special economic zones, on 31 December 2006, Ministry of Economy, Warsaw, May 2007, Information on the implementation of the Law on special economic zones, on 31 December 2008, Ministry of Economy, Warsaw, May 2009, Information on the implementation of the Act on special economic zones, as on 31 December 2010, Ministry of Economy, Warsaw, May 2011.

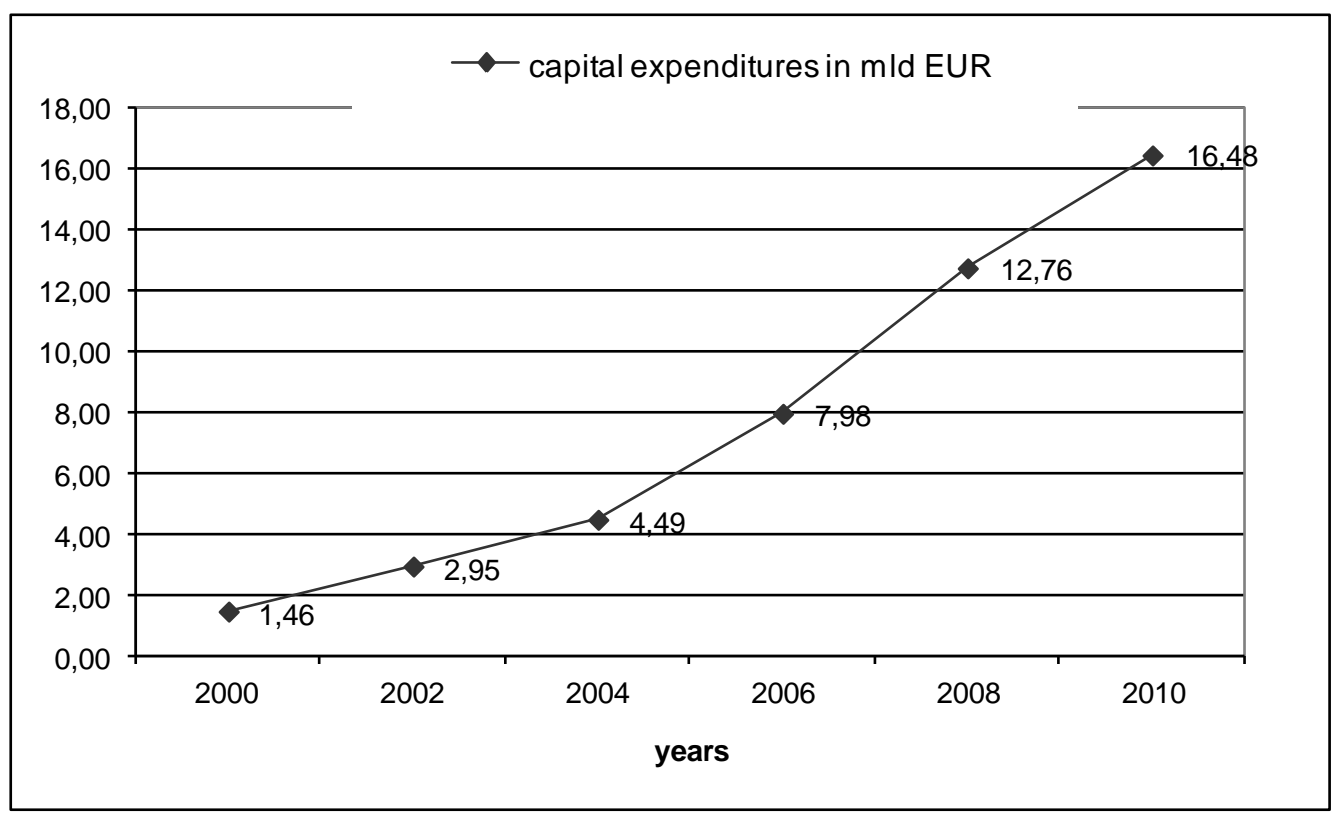

Figure 2. Capital expenditures in the SEZ in the years 2000 to 2010.

Source: own, based on reports: Special economic zones, as of December 31, 2004, Ministry of Economy and Labour, Warsaw, March 2005, Information on the implementation of the Act on special economic zones, on 31 December 2006, Ministry of Economy, Warsaw, May 2007, Information on the implementation of the Law on special economic zones, on 31 December 2008, Ministry of Economy, Warsaw, May 2009,I Information on the implementation of the Act on special economic zones, as on 31 December 2010, Ministry of Economy, Warsaw, May 2011. 
obsolete structure of the economy has not benefited significantly from the adjusted changes. What is more, negative phenomena emerged there, in an unprecedented scale. Unemployment, the accompanying low standard of living and social exclusion of some citizens motivated public authorities to search for instruments, which could be used to counteract the negative trend. Among them an important role played and still play SEZ.

Originally SEZ were to operate for 20 years since their creation. Successive amendments of the law about special economic spheres prolonged their action to 2020. There is still ongoing lively discussion whether, and this time limit should be postponed, perhaps even without a time limit. It seems that the continued functioning of the SEZ depends on economic and social- political factors. In the political sphere, mainly the shape of the future EU regional policy should be mentioned. Public aid granted in the zones must be compatible with European law, which in subsequent EU budgetary perspectives may change. It should be noted that in Poland in political circles there is a consensus for further existence of these institutions. The second factor is the overall economic and political situation- in the country and in the world. It could be adopted, that investment decisions often depend on it. Changes may pre-empt the advisability of existence of further zones. Among the factors of economic and social character, the question of unemployment and related phenomena is the most important. The high level of unemployment will further impetus for cementing anxiety to maintain the SEZ. It is worth noting that the revised law about special economic spheres stresses the importance and grant a privileged position to those which are innovative in nature. The growing importance of this type of action in a SEZ would impact on improving the competitiveness of Poland and its regions and thus become another argument for an extension of their operation.

SEZs are macroeconomic instrument of regional Policy. Practice shows, however, that regional and local authorities are the initiators of action aimed at the creation and operation of the zones. The law says that local authorities must agree to the creation zone, community representatives may become the members of the board. The special role that falls to local authorities in the process of acquiring investors is worth emphasizing. Through marketing and creating a good climate for investment the local government can significantly contribute to the success which is creation and efficient action of SEZs.

The role of the SEZ is visible at the macroeconomic level, regional and local levels. Due to the limited use of in SEZ property tax, and income tax exemptions, benefits for the economy should be seen primarily in the strong stimulus of development which it receives when the new business is situated there. Each new investment, generating new jobs contributes to the reduction of unemployment, increase of the employment, and thus to increase in the incomes of the population. The increase in wealth of the society has a direct impact on increased demand in turn. If there are savings, in addition, with the participation of the banking sector there may be further benefits in the form of new investments. All these elements lead to an increase in income budgets, the improvement in the quality of life for citizens may occur at the same time.

\section{REFERENCES}

Bartosiewicz B, Marszal T (2011). The economy of the small cities from the perspective of the 20 years in transformation. Lodz University press, Poland 82.

Czerwinska E (2000). The problem of special economic zones in Poland. Office of Research of the Sejm (lower house of the Polish parliament) Chancellery, Department of Economic and Social Analysis 751:5-6.

Fiedor B (2007). Walbrzych Special Economic Zone INVEST-PARK: the balance of the first decade impact on the region and prospects for development. University of Economics in Wroclaw press, Wroclaw, Poland.

Filipiak B, Kogut M, Szewczuk A, Ziolo M (2005). Local and regional development - conditions, finances, procedures. Foundation for the University of Szczecin, Szczecin, Poland p.363.

Gwosdz K, Domanski B (2005). Ten years of experience of the first Polish special economic zone. Mielec 1995-2000. The Institute of Geography and Spatial Management, Jagiellonian University, Mielec, Poland pp.35-36.

Jaslan W (2009). Special economic zones. The Economy of Materials Technology and Logistics 3:29-30.

Kirylo J (2000). Special Economic Zone as an instrument of regional policy. The work of the Institute of Materials and Functioning of National Economy, Poland 80:155-156.

Krynska E (2000). Polish Special Economic Zones. Scientific Scholar press, Warsaw, Poland 34.

Krynska E (2000a). Polish Special Economic Zones - views and the effects. European Institute of Regional and Local Development, UW, Warsaw, Poland pp.9-11.

Mikolajewicz Z (2000). Circumstances and strategies of regional development in EU integration processes. Polish Economic Association, The University of Opole, Opole, Poland pp.431-441.

Przybyla K (2010). Impact of the special economic zones on the development of cities economic base. University of Environmental and Life Sciences press, Wroclaw, Poland 8:66.

Przybyla K (2010a). Impact of Walbrzych special economic zones on the labour market in Walbrzych subregion. Econ. Organ. Enterprise 9:80.

Sadowski Z (1999). Foreign capital in Poland. Operating conditions. Polish Economy Association, Warsaw, Poland pp.35-64.

Smith D (1966). A theoretical framework for geographical studies of industrial location, Econ. Geogr. 42:95-113.

Trojak A, Wiedermann K (2009). Special economic zones and industrial zones in the shaping of regional industrial development on the example of Poland and Czech Republic. Works of the Commission of Geographical Industry 12:134

\section{Acts and reports}

Information about the implementation of the law on the special economic zones, situation at 31 December 2006. Ministry of Economy, Warsaw, May 2007: 11-13.

Information about the implementation of the law on the special economic zones, situation at 31 December 2008. Ministry of Economy, Warsaw, May 2009: 15-17.

Information about the implementation of the law on the special economic zones, situation at 31 December 2010. Ministry of Economy, Warsaw, May 2011: 9-10, 12, 14, 18.

Law on the special economic zones from 20 October 1994 with later 
amendments.

Report: Special Economic Zones after 2020. Analysis of current activities and the perspective of the operation. Ernst \& Young Poland, 2011: 8, 41.
Special economic zones, as on 31 December 2004, the Ministry of Economy and Labour, Warsaw, March 2005: 11, 13, 15-16. 